\title{
Otras consecuencias de la crisis en la sostenibilidad de los servicios sociales de ámbito local en la Comunidad Valenciana
}

\author{
Xavier Montagud Mayor \\ Universitat de Valencia \\ javier.montagud@uv.es
}

\begin{abstract}
Tokiko entitateak laurogeiko hamarkadaren bukaeran ezarri zituzten Valentziako Autonomia Erkidegoko gizarte-zerbitzu orokorren sistemarako zutabe eta sarbide gisara. Krisialdi ekonomikoaren ondorioz, larrialdi sozialak gainditu egin du tokiko erakunde horien ahalmena. Azalpenetako baten esanean, murrizketek eta baliabide eskasiek gertarazi dute egoera hori, halere, artikulu honetan erakusten denez, ahultasun hori ez dator krisialdiaren ondorioz, baizik eta sistema ezarri zeneko ezaugarri batengatik. Ezaugarri bereizgarri horrek azaltzen ditu garai berri honetan misioari eusteko agertzen diren zailtasunak. Beraz, iradokitzen dugu baldintza horien ondorioz gertueneko eskuartzea modu zabal batean ulertzea, eta horretarako gehitu ahal izatea bestelako ekimen sozial mota desberdin batzuek, eta horien bitartez aurre egitea aldi berean egongo diren kalteberatasun, zaurgarritasun eta ezegonkortasunari, alde batetik, eta bazterkeria eta pobrezia modu tradizionalei, bestetik.
\end{abstract}

\section{GAKO-HITZAK:}

Valentziako Autonomia Erkidegoa, krisialdia, udalerriak, gizarte-zerbitzuak, iraunkortasuna, Oinarrizko Prestazioen Hitzartutako Plana.
Al final de la década de los ochenta se implementaron en la Comunidad Valenciana los servicios sociales generales como pilar y puerta de entrada al sistema desde las entidades locales. Con la crisis económica, estos se han visto sobrepasados por la situación de emergencia social. Una de las explicaciones más habituales es achacarlo a los recortes y la insuficiente dotación de medios. Sin embargo, este artículo revela que su debilidad no es fruto de la crisis, sino un rasgo constitutivo desde su implantación. Este hecho diferencial muestra las dificultades para sostener su misión por sí solos en esta nueva época. Sugerimos, por consiguiente, que en estas condiciones se entienda la intervención social de proximidad de un modo más amplio, incorporando otro tipo de iniciativas sociales que permitan afrontar un escenario en el que la vulnerabilidad, la fragilidad y la precariedad convivirán con las tradicionales formas de exclusión y pobreza.

\section{Palabras Clave:}

Comunidad Valenciana, crisis, municipios, servicios sociales, sostenibilidad, Plan Concertado de Prestaciones Básicas. 


\section{Introducción}

Con cierta periodicidad, el nivel básico de los servicios sociales recupera el primer plano en la agenda de la política social. Cuando así ocurre, se reivindica su papel como "puerta de entrada" o "eje vertebrador", mientras se pone énfasis en los principios de universalidad, proximidad, responsabilidad pública o integralidad. Durante los últimos años parece renovarse su interés. Desde la publicación del estudio coordinado por Subirats (2007) se han sucedido los estudios sobre el impacto que la crisis ha tenido sobre esta esfera de los servicios sociales (Alguacil, 2012; AEDGSS, 2013; Aguilar, 2014, Rodríguez Cabrero, 2012). A estos trabajos se han sumado otros desde distintas instancias administrativas, con especial extensión y profundidad, desde algunas oficinas del Defensor del Pueblo autonómicas. Al mismo tiempo, su situación ha sido objeto de intenso debate desde diferentes espacios (colegios, congresos y jornadas, plataformas de defensa, etc.) que han abordado los problemas a los que este nivel de la intervención social se enfrenta.

Aunque reciben diferentes nombres según la legislación de cada Comunidad Autónoma (atención primaria, base, comunitarios, etc.), los servicios sociales generales son considerados la estructura básica del sistema, que distingue entre ellos y los servicios sociales especializados. Su actuación tiene carácter universal y gratuito, garantizando la atención de manera integrada y polivalente a las personas a las que presta ayuda. Por el contrario, los servicios sociales especializados se orientan a sectores de población que por sus especiales condiciones requieren de un tipo de atención específica desde el plano técnico y profesional. Por consiguiente, su acceso está condicionado al cumplimiento de unos requisitos que en algunos casos pueden suponer una contraprestación económica. De otra parte, mientras el primer nivel se presta por parte de equipos multidisciplinares cuya titularidad es siempre pública y cuya gestión corresponde a las Administraciones Locales (ayuntamientos, mancomunidades y diputaciones provinciales), en el segundo nivel pueden participar otros agentes (ONG, empresas, etc.).

Los servicios sociales generales comprenden un amplio conjunto de servicios y programas. Informan, orientan y proporcionan asesoramiento técnico acerca de los derechos y los recursos que la Administración y otras instituciones ponen a disposición de las personas y colectivos. Promueven la prevención y reinserción de los individuos y grupos en situación de carencia o exclusión. Prestan la ayuda a domicilio con el fin de posibilitar la permanencia de las personas en su medio y ofrecen recursos convivenciales a las personas que no disponen de ellos. Por último, atienden mediante la gestión de prestaciones y ayudas económicas las necesidades básicas de las personas y en bastantes casos incluso desarrollan programas de promoción del ocio y el tiempo libre. Su fin es promover el desarrollo pleno del individuo y de los grupos en que se integra, potenciando su participación en la búsqueda de recursos y priorizando las necesidades más urgentes y básicas. Se erigen pues en la primera red de proximidad a los ciudadanos ya que se sitúan en la posición geográfico-administrativa más cercana, la local, desde la que dan cobertura a la mayoría de la población. A este respecto, conviene saber que la tasa oficial de cobertura de derecho (es decir, la accesibilidad a este nivel de los servicios sociales) se sitúa desde hace años en torno al $95 \%$ de la población (PCPB, 2014).

No obstante, aunque fueron concebidos inicialmente como un espacio desde el que promover el desarrollo de las personas, grupos y comunidades más desfavorecidas, la aparición de nuevas problemáticas y carencias, junto con el desarrollo de nuevos derechos individuales les ha forzado a asumir competencias de otros sectores de la intervención social (menores, mayores, discapacidad, etc.), lo que les ha obligado a prestar en muchos casos servicios especializados (intervención familiar socioeducativa, prestaciones para mayores, gestión de plazas, etc.) que no habían sido previstos. Estos cambios y la llegada de la crisis económica han acabado por transformar los servicios sociales generales, hasta el punto de que hoy son evidentes los signos de crisis de identidad, capacidad y objetivos (Aguilar, 2013; Fantova, 2014; Pelegrí, 2015). Un dato podría resumir este especial momento: pese al dato formal de cobertura señalado, la tasa de cobertura directa (es decir, la población que hace uso efectivo de los sistemas de servicios sociales generales) no ha sobrepasado conforme al Ministerio de Sanidad, Servicios Sociales e Igualdad el $12 \%$ de la población española (PCPB, 2014), mientras que el indicador de pobreza europeo AROPE para ese mismo año se situó en el 29,9\% (Eurostat, 2015). Si añadimos que, conforme al estudio de Tezanos et al. (2013) sobre la situación de las familias en situación de vulnerabilidad en España, el $93 \%$ de las que fueron entrevistadas no habían recibido ayuda de ningún organismo público o privado, y de las que sí, un $57 \%$ la obtuvieron de organismos públicos y un $29 \%$ a través de entidades del tercer sector, comprenderemos la encrucijada en la que se encuentra esta esfera de los servicios sociales frente a la crisis. Este lance nos lleva a contemplarlos como un sistema de vocación universalista pero focalizado en las personas, grupos y colectivos en situación de especial dificultad, pobreza o exclusión con grandes impedimentos para atender los problemas derivados de los cambios y nuevos riesgos de la sociedad del bienestar.

El caso de la Comunidad Valenciana no es una excepción. Los datos sobre vulnerabilidad y pobreza (EAPN-España, 2016; FOESSA, 2014) y servicios sociales (AEDGSS, 2015; Martínez y Uceda, 2015; MSISS, 2015; Síndic de Greuges, 2013, 2017) apuntan a la debilidad extrema del sistema, lo que le habría impedido contrarrestar las manifestaciones más 
extremas de la crisis y paliar sus necesidades vitales. Ahora bien, la opinión aquí defendida es que esta crisis ha ido más allá, al poner al descubierto las limitaciones de un discurso que sigue centrado en la gestión de los recursos de proximidad exclusivamente desde lo público. Desde este marco son reconocibles las importantes limitaciones para afrontar un escenario en el que todo apunta a la permanencia, extensión e incluso intensificación de la pobreza y la exclusión, mientras las dificultades de financiación para sostener las crecientes demandas y exigencias de la ciudadanía probablemente continuarán. En conjunto, estos hechos insinúan la fractura del paradigma sobre el que se ha venido asentando la fundación de los servicios sociales de atención primaria, a la vez que pone en entredicho su sostenibilidad, entendida aquí como la capacidad para cumplir con la misión para la que fueron creados, en este nuevo entorno. Sin embargo, al mismo tiempo es también una oportunidad para la innovación y la transformación de un sector que no ha cambiado demasiado en su estructura en los últimos treinta y cinco años.

Este es el punto de partida. Me pregunto cómo han afectado todos estos cambios al sistema de servicios sociales generales en la Comunidad Valenciana (CV, en adelante) y si es posible que en tales condiciones puedan sostener los objetivos para los que fueron creados. A tal fin, se analiza en primer lugar el marco general de la financiación de los servicios sociales generales en España, exponiendo su evolución hasta hoy y apuntando algunas consideraciones para el caso particular de la CV. Posteriormente se describe el impacto de la crisis en la sociedad y los servicios sociales valencianos, así como el alcance de la respuesta de sus Administraciones hasta 2015. Como consecuencia, en el tercer apartado se plantea la posibilidad de que estas dificultades sugieran no únicamente problemas de sostenibilidad, sino también límites en su estructura en el contexto de cambio de época en el que nos encontramos, que se manifiesta en algunos conflictos de la intervención de los servicios sociales. Cierra el artículo un breve esbozo sobre las otras consecuencias de la crisis y el cambio de época para los servicios sociales de proximidad para el que apostamos por un modelo más abierto y colaborativo que complemente las insuficiencias del actual.

\section{Financiación de los servicios sociales generales}

Con la llegada de la democracia se desarrolló en España una política tendente a equiparar nuestro país a los parámetros del Estado de Bienestar del que ya disfrutaban otros países de nuestro entorno. Una de las decisiones fue establecer un sistema público de servicios sociales que permitiera, de acuerdo con la formulación constitucional, prevenir o eliminar las causas que llevan a la marginación, aunque delegando esa competencia en las comunidades autónomas. La aprobación de las primeras leyes autonómicas de servicios sociales y de la Ley 7/1985 reguladora de las Bases del Régimen Local señaló que el municipio ejercerá las competencias “en materia de prestación de los servicios sociales y de promoción y reinserción social". Esta situación y la necesidad de articular unas prestaciones y servicios básicos para todo el Estado llevarán en 1988 a implantar un modelo de cooperación económica y técnica que permitirá implantar una red básica de atención de servicios sociales en los municipios: el Plan Concertado de Prestaciones Básicas de Servicios Sociales (PCPB). El Plan Concertado sigue siendo hoy, a pesar de todo, el principal instrumento de cooperación técnica y financiera de alcance estatal en esta materia. Por consiguiente, aunque no represente el cien por cien del Estado ni de los presupuestos globales de servicios sociales en el ámbito local, es una de las escasas herramientas objetivas de las que disponemos para analizar largos espacios temporales para el conjunto del territorio o por comunidades autónomas o entidades locales. Sobre él encontramos dos buenos estudios. En el primero, Gutiérrez Resa (2003) describe con detalle los antecedentes del plan, el procedimiento para su implantación y su evolución durante los primeros once años. Acierta al plantear sus logros y defectos pero, sobre todo, formula algunas propuestas de mejora que hoy continúan siendo válidas y necesarias. El segundo, un estudio de Aguilar (2014) para Foessa incorpora los efectos que la Ley de Dependencia y las ya evidentes consecuencias que la crisis tiene en los sistemas, reincidiendo en algunas de las explicaciones sobre su problemática. La lectura de ambos y el análisis de las memorias del plan permiten conocer cómo ha evolucionado en su contenido y alcance, obtener datos sobre sus presupuestos, grado de responsabilidad financiera, conceptos de gasto, personas atendidas, etc.

Como principio, el PCPB contempla el establecimiento de convenios-programa de colaboración entre tres niveles administrativos (Estado, comunidades autónomas y entidades locales) para financiar los siguientes conceptos:

- Ayudas para el pago de salarios y seguridad social de los profesionales de los equipos sociales de base.

- Ayudas para el mantenimiento de centros sociales.

- Ayudas para los programas de prestaciones básicas consignadas en el apartado anterior.

En el caso concreto de la Comunidad Valenciana, es la vicepresidencia y Conselleria de Igualdad y Políticas Inclusivas la que suscribe ese plan con el Ministerio mediante fondos condicionados y fondos del Estado. Posteriormente, mediante convocatoria anual, se hace partícipes del plan a los municipios, estableciendo las obligaciones financieras para cada parte. No obstante, coexisten otras vías de financiación. De una parte, el Estado ofrece otras convocatorias complementarias al Plan 
Concertado (por ejemplo, las de lucha contra la pobreza infantil o las de ayuda al pueblo gitano). De otra, la administración autonómica destina fondos propios no condicionados a los servicios sociales municipales (prestaciones económicas, inclusión social, programas de intervención familiar, etc.) mientras las diputaciones provinciales financian con recursos propios a municipios de menor tamaño no vinculados a este plan o que precisan de un apoyo financiero complementario. Por último, cabe tener en cuenta que las entidades locales completan sus necesidades con aportaciones propias aunque a menudo no identificables. Como consecuencia, toda esta multiplicidad de vías de financiación y la forma en que se reflejan distorsiona el acercamiento a la materia y obliga a ser cautos en sus resultados.

Al analizar la financiación del PCPB para todo el Estado (salvo País Vasco y Navarra) desde 1988 hasta 2014 observamos que, en términos generales, su volumen ha crecido de manera sostenida hasta 2011, siendo el mayor aumento el que se produce precisamente en la fase inicial de la crisis (20082009) para iniciar posteriormente el declive de las aportaciones al Plan. El Gráfico 1 refleja su evolución, que se corresponde con las tres etapas que la mayoría de autores manejan para explicar la historia de los servicios sociales. A la fase inicial de fuerte expansión del gasto (hasta mediados de los noventa) se corresponde la puesta en marcha de los primeros equipos y programas de servicios sociales. Le sigue después una fase moderada (1995-2005), con incrementos planos, en los que se intuye la pérdida de importancia del PCPB en el conjunto del gasto del sistema de servicios sociales. Esta situación se corresponde con la fase de diferenciación de los sistemas autonómicos de servicios sociales y con el auge de los servicios sociales especializados. El gasto imputable al plan solo volverá a crecer con intensidad a partir de 2005 , coincidiendo con una fuerte expansión del gasto público y con la aprobación de la LAPDA, que insuflará nuevos aires a las partidas de servicios sociales generales hasta la explosión de la crisis.

Sin embargo, en el caso concreto de la CV esta evolución presenta ciertas peculiaridades. En el Gráfico 2 hemos representado el esfuerzo comparativo entre el conjunto del Estado y la CV desde 1988 hasta 2013 (última memoria disponible del MSSSI) para lo cual medimos el porcentaje interanual de crecimiento en ambos. Si tomamos el primero como referencia, comprobamos que el esfuerzo para desplegar los servicios sociales generales en la CV fue durante sus primeros ocho años inferior. Al mismo tiempo, su esfuerzo presupuestario está sometido a continuos cambios de ritmo, con avances y retrocesos sucesivos, frente al comportamiento más homogéneo durante esos años en el conjunto nacional. Por último, únicamente en dos breves periodos de tiempo (1996-1999 y 2003-2005) el esfuerzo de la CV fue similar o mayor que el del conjunto del Estado. Esa diferencia en el ritmo y cuantía de la inversión en la CV durante los primeros años es la que ha condicionado a lo largo del tiempo sus posibilidades. No es pues de extrañar que, cuando se difumine a mediados de los noventa el papel impulsor del Plan Concertado, el proceso de construcción y consolidación de los equipos base en la CV sea frágil e incompleto. Esa circunstancia va a coincidir con un proceso más amplio de individualización y ascenso del ciudadano-consumidor (Ritzer, 1999) que destruye la idea comunitaria en la que estaban basados los servicios sociales generales. A partir de ese momento el usuario pasa a ser considerado como consumidor de una cartera de servicios, idea que impone la tendencia a crear prestaciones y servicios especializados y detener el impulso a la financiación y dotación de la atención primaria.

Gráfico 1. Aportación total de las Administraciones Públicas al Plan Concertado de Prestaciones Básicas de Servicios Sociales (PCPB) en millones de euros (1988-2013)

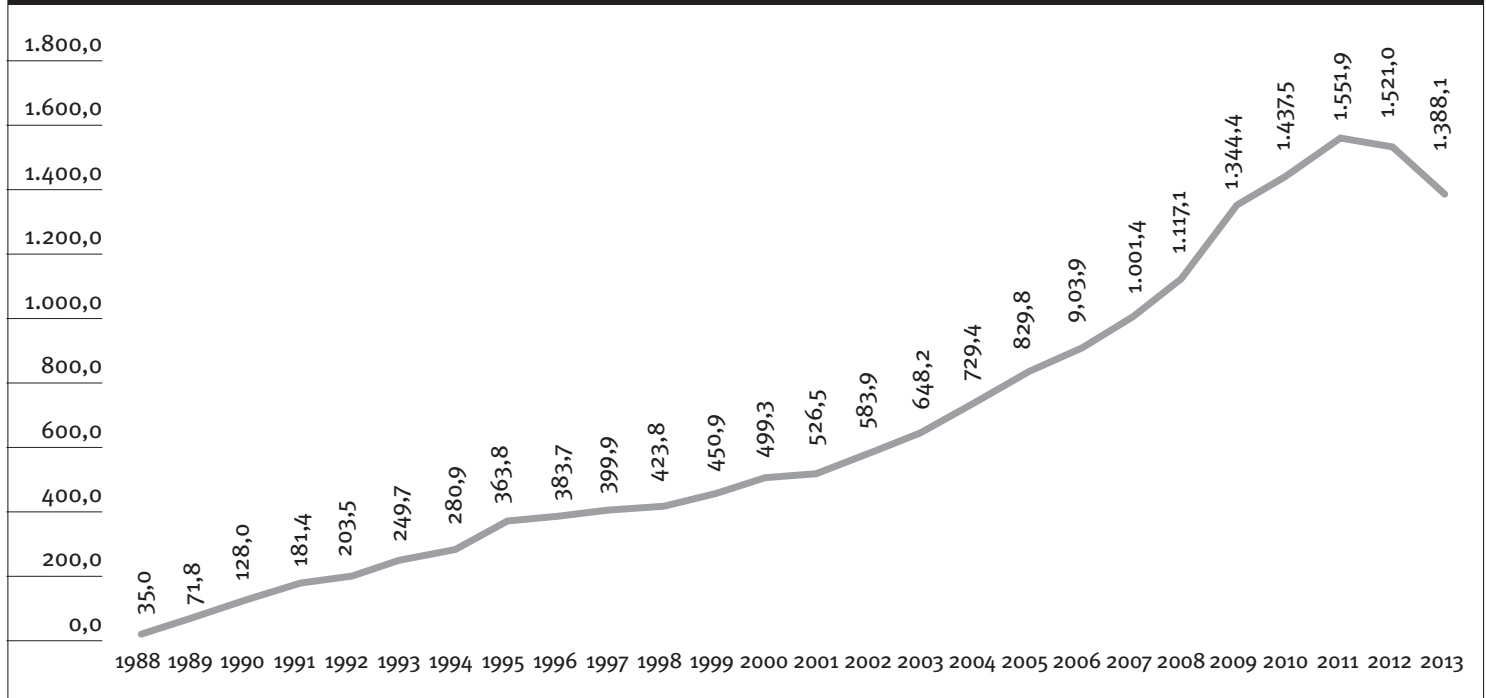

Fuente: Elaboración propia. 


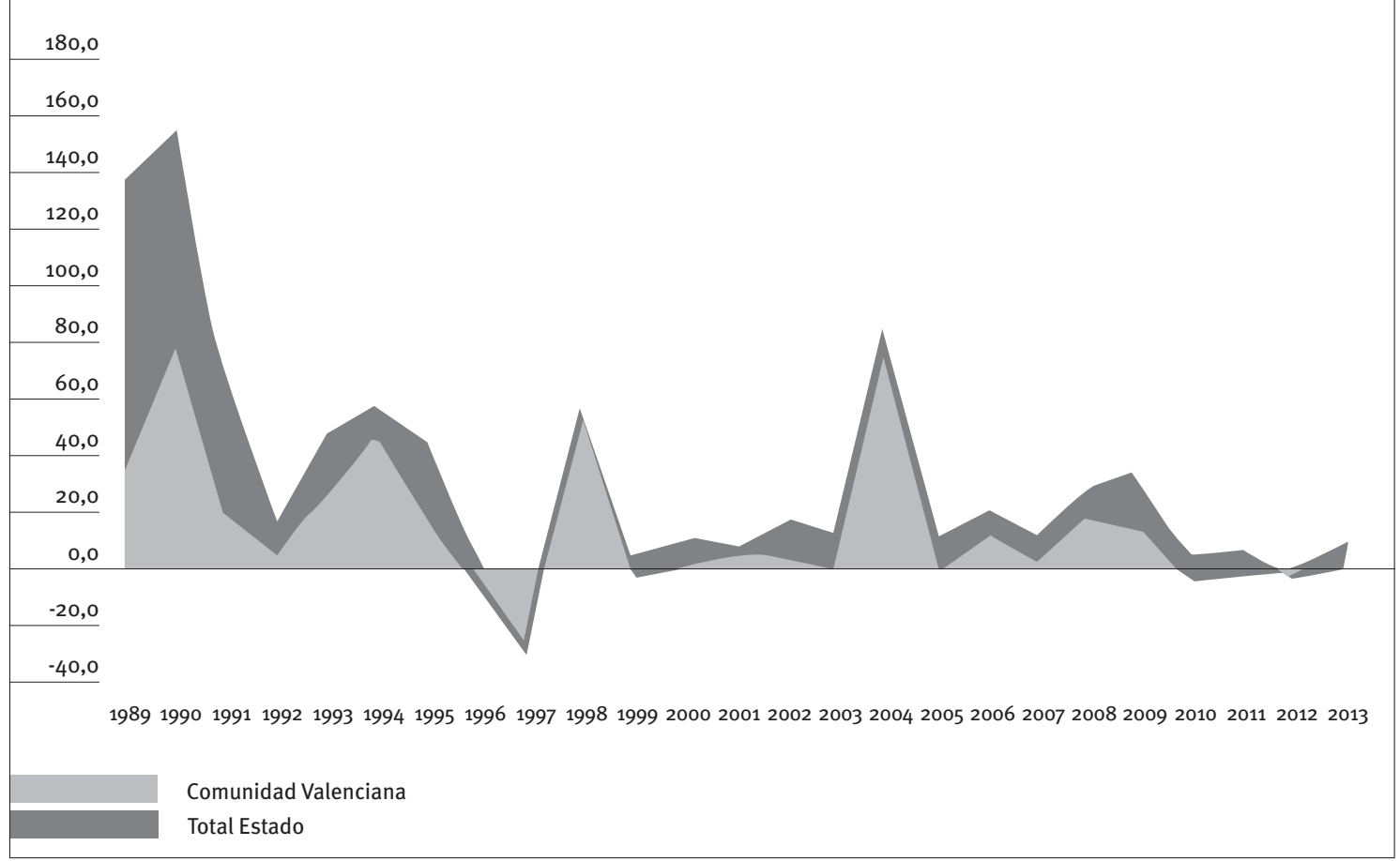

Fuente: Ministerio de Sanidad, Servicios Sociales e Igualdad (PCPB, 2015).

Si analizamos el porcentaje de participación de las distintas Administraciones en la financiación del PCPB (Gráfico 2), se comprueba el paulatino abandono del Estado y la asunción de este papel por parte de las comunidades autónomas. Desagregando las aportaciones, pueden distinguirse dos periodos. En el primero, el peso de la participación recae fundamentalmente en las entidades locales (19932008), que de forma muy distinta se comprometen al mantenimiento de los servicios y prestaciones. Posteriormente, en el segundo, y ya como efecto de la crisis y de la entrada en vigor de las medidas de limitación del gasto en las entidades locales, son las CC.AA. las que asumen las necesidades de financiación que no pueden ser atendidas por las otras dos. No obstante, y como muestra el gráfico, a partir de 2011, el volumen total del PCPB no ha hecho sino ver disminuir las aportaciones de los tres ámbitos administrativos.

A pesar de que la retirada paulatina del Estado en la financiación de los servicios sociales generales es presentada habitualmente de manera negativa, debe interpretarse como una consecuencia lógica de la asunción por parte de las CC.AA. de sus competencias exclusivas a falta de una regulación estatal que obligue al Estado a hacerlo. No obstante, una de las consecuencias de esa retirada es la quiebra de un modelo único de servicios sociales, que ha conducido a que cada comunidad establezca su propio sistema sobre la base de esos mínimos, con un compromiso financiero muy distinto, lo que condicionará a posteriori las posibilidades de intervención durante la crisis.
El análisis de la evolución de la distribución del gasto según se destina a prestaciones económicas o a sufragar la contratación de personal (Gráfico 3) apunta en esa misma dirección. A un periodo inicial, centrado en la contratación de profesionales con quienes configurar los equipos base municipales (1988-1992), le sigue otro más amplio (1993-2004), en el que este capítulo pierde importancia en beneficio de las prestaciones. Un proceso que se ha visto acelerado por la crisis, que llevó a concentrar los esfuerzos en las ayudas económicas y técnicas. Esa tendencia general tiene varias implicaciones. Podría inferirse que desde mediados de los noventa se da por finalizado el proceso de configuración de los servicios sociales de atención primaria y se opta por potenciar los servicios sociales especializados (de atención a tercera edad, discapacidad o menores). Esto tendrá efectos notables en el caso de la CV cuando estalle la crisis, al no haber podido o querido desarrollar un sistema básico potente y bien dotado. También se intuye un cambio en la fórmula de provisión de los servicios sociales. De un modelo fundamentalmente público pasamos al modelo de concertación con entidades del tercer sector, al tiempo que se asiste a la creciente mercantilización de ciertos sectores de la atención social, especialmente en el de la tercera edad. El resultado es que paulatinamente los servicios sociales generales van quedando relegados en la política estatal y autonómica en favor de servicios sociales de atención a problemáticas específicas, perdiendo visibilidad e importancia. 


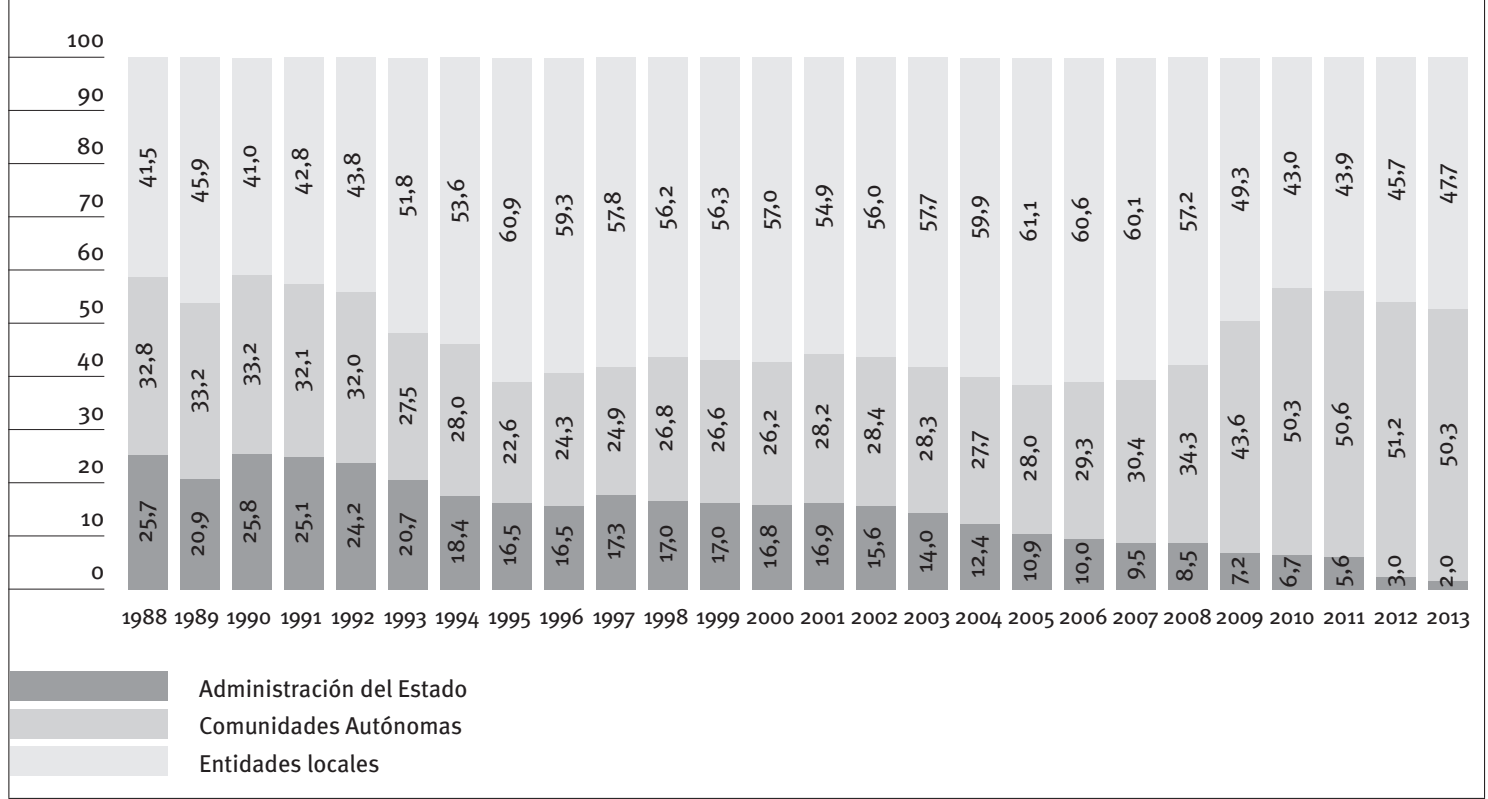

Fuente: Ministerio de Sanidad, Servicios Sociales e Igualdad (PCPB, 2015).

Gráfico 4. Evolución del gasto en prestaciones y personal en el PCPB (1988-2013)

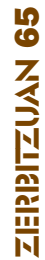

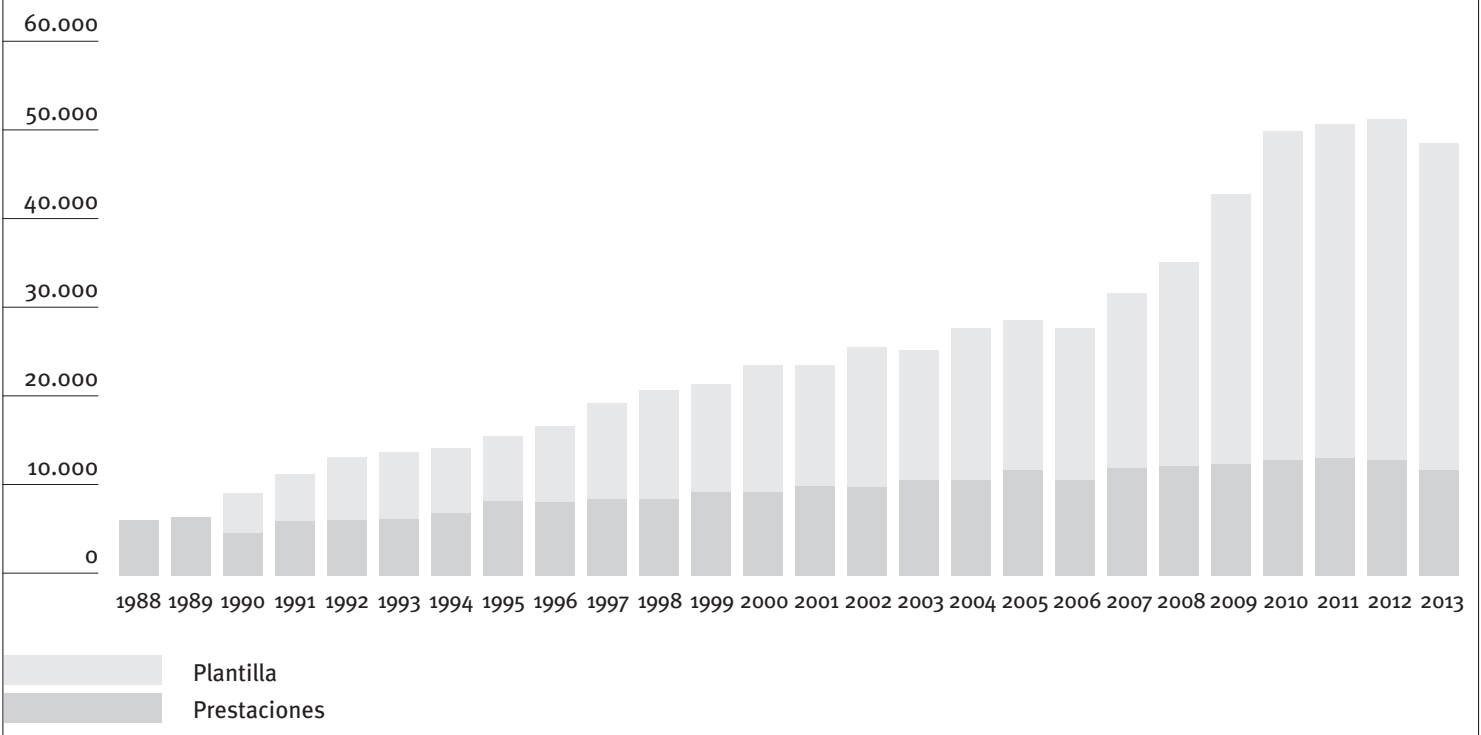

Fuente: Ministerio de Sanidad, Servicios Sociales e Igualdad (PCPB, 2015).

Otro argumento con el que comprobar la pérdida gradual de interés en los servicios sociales generales es fijarnos en su número de profesionales. Conocemos por las memorias del ministerio que el personal financiado con cargo al PCPB en España pasó de 1.834 profesionales en el año 1988 a 50.007 en el 2012. Sin embargo, en ese mismo periodo, el estudio de Rodríguez Cabrero (2012) muestra que la fuerza laboral del conjunto del sector de servicios sociales aumentó desde los 49.000 trabajadores a los 484.000 en 2010. Un estudio posterior de la Fundación Luis Vives (2012) desvela la causa. El tercer sector en
España contabilizaba 635.961 trabajadores en el año 2010. Es pues evidente que el crecimiento de la masa laboral se ha trasladado de los servicios sociales generales (que por obligación normativa han de ser públicos) a los especializados, y de lo público al tercer sector y al sector mercantil, reduciendo el peso del sector público como generador directo de empleo y, por tanto, como objeto preferente de financiación.

Para completar la idea sobre la pérdida de importancia del PCPB y de los servicios sociales de atención primaria sobre el modelo de servicios 
sociales, compararemos el presupuesto de las tres administraciones implicadas en el plan con el presupuesto que se destina a toda la rama de los servicios sociales. Lo haremos tomando los datos de la Comunidad Valenciana. Si confrontamos el gasto global del departamento con competencias en la materia con el gasto global del PCPB para la CV (todas las Administraciones), verificamos que su porcentaje no ha variado en los últimos catorce años (del 10,6\% en 2001 al 11,9\% en 2014). Si analizamos en términos estrictamente internos, la financiación del plan en relación con el total del gasto de la Generalitat Valenciana en servicios sociales y promoción social, comprobamos que el peso del primero se ha reducido ostensiblemente, pasando del 4,4\% en 2001 al 2,4\% en 2014. De hecho, aunque durante el ejercicio 2017 la Generalitat Valenciana contempla duplicar la partida del PCPB, su volumen continuará situándose en el $4,46 \%$ de su presupuesto global, porcentaje muy similar al de 2001. Con todo esto queremos significar que los servicios sociales de atención primaria en la CV, a pesar de que sobre el papel se consideren el pilar del sistema, han estado desde sus inicios infrafinanciados e infradotados si los comparamos con otros territorios de condiciones socioeconómicas semejantes. Hoy sus presupuestos no alcanzan ni de lejos los destinados a sectores de servicios especializados como la protección de menores o la atención a la diversidad funcional, y mucho menos si los cotejamos con los dedicados a la atención especializada de la tercera edad.

\section{Impacto y respuestas a la crisis en la Comunidad Valenciana}

La depresión económica ha supuesto un duro revés para los servicios sociales de atención primaria al verse desbordados por el número de personas y familias que acudían solicitando algún tipo de ayuda y comprobar cómo eran sobrepasados por la agilidad del tercer sector para organizarse y responder con rapidez a los retos de esta nueva situación. Todo en un entorno en el que se redujeron significativamente los recursos humanos disponibles, mientras el ligero crecimiento de sus presupuestos no conseguía cubrir ni de lejos el aumento y la urgencia de las necesidades. Para comprobarlo, tomaremos de Lluch, Esteve y Gimeno (2015) dos magnitudes de su estudio sobre la recesión en la población de la CV: la incidencia e intensidad de la pobreza y el nivel de integración/exclusión.

Si atendemos en el Gráfico 5 a la evolución de los índices de pobreza y exclusión de la CV entre los años 2004 y 2013 (periodo que comprende años anteriores y posteriores a la recesión) y los comparamos con los datos nacionales, observamos que esta comunidad ha mantenido en general un índice de pobreza ligeramente superior al del conjunto nacional. Llaman especialmente la atención sus rápidas y bruscas oscilaciones, comportamiento que en buena medida puede reflejar un mercado laboral excesivamente estacional, centrado en los servicios y la agricultura. La misma tendencia se observa en el grado de intensidad de la pobreza, es decir, en el promedio entre las personas en riesgo de pobreza y el umbral de pobreza fijado en ese momento. En todos los casos su comportamiento es ligeramente superior al de la media nacional, de lo que se desprende que las personas en situación de pobreza en nuestra comunidad son cada vez más pobres. Incluso en ciertos momentos, más que las personas de su mismo grupo de análisis de otros territorios (EAPN, 2016). De este modo, comprobamos que la Comunidad Valenciana ha sido y es más sensible a

Gráfico 5. Evolución de la incidencia e intensidad de la pobreza en España y la CV (2004-2013)

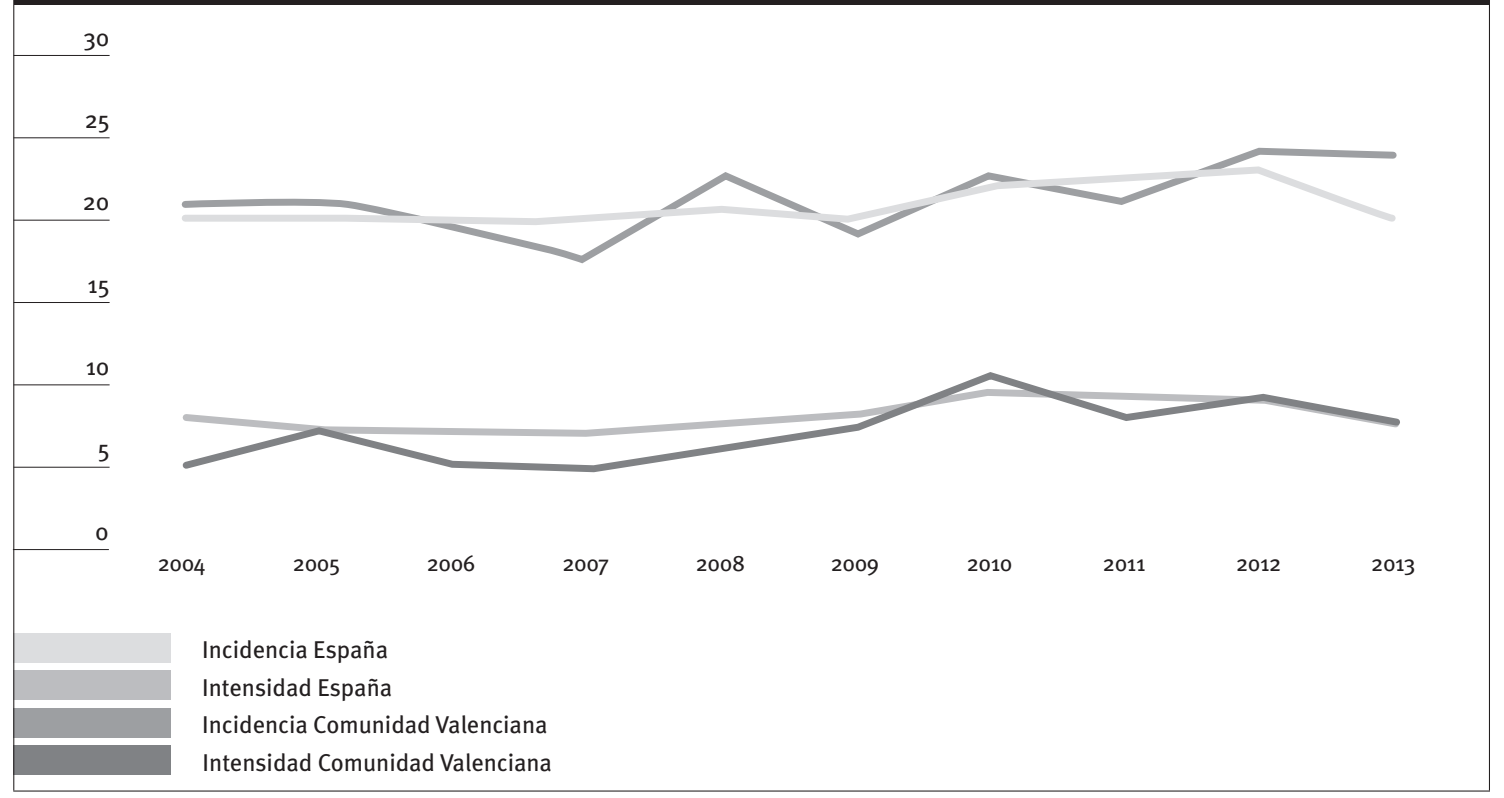

Fuente: Lluch y Esteve (2015). 
los efectos de las crisis sobre el comportamiento de la pobreza, ya que reacciona negativamente antes que el conjunto nacional y, por el contrario, encuentra mayores resistencias a evolucionar positivamente.

El Gráfico 6 complementa la fotografía sobre la exclusión y la pobreza en la CV. Representa los niveles de integración/exclusión de los hogares según su agrupación en cuatro perfiles en un momento dado. En él se revela que el porcentaje de hogares en situación de exclusión severa y moderada suponen en 2013 más del 50 \% y que este ha crecido más en la Comunidad Valenciana que la media nacional. Los datos además indican que el impacto de la crisis ha sido más acusado y virulento que en otras comunidades con condiciones similares.

En resumen, podemos decir que la CV se ha visto afectada profundamente por la crisis. Sus tasas de incidencia de la pobreza extrema o relativa y de pobreza infantil, que ya se situaban por encima de la media nacional, han empeorado. No sabemos si el cambio de tendencia de 2016 supone el inicio de la recuperación y mejora de estos indicadores o la confirmación de encontrarnos ante un cambio de ciclo histórico. El hecho es que la crisis ha engrosado significativamente el número de personas y familias en situación de vulnerabilidad, pobreza o riesgo de exclusión, y que los servicios sociales generales de la CV están lejos de disponer de la capacidad y los medios necesarios para ayudar a detenerlas 0 paliarlas por sí solos.

Frente a este escenario, cabría haber esperado de las Administraciones Públicas un esfuerzo importante centrado en paliar los efectos más graves de la crisis. Especialmente en aquellos sectores de población en situación de exclusión severa con quienes los servicios sociales de atención primaria mantienen un contacto directo, pero también con quienes se adentran en ese espacio de vulnerabilidad por primera vez. Lamentablemente, como mostraremos, las Administraciones Públicas valencianas no pudieron o no hicieron ningún esfuerzo reseñable en ese sentido. Pese a que el presupuesto de la Generalitat Valenciana es el cuarto en volumen, no hay señales de que este asunto ocupara algunas de sus primeras líneas de decisión política y económica, como ilustra la evolución del presupuesto de la Conselleria de Bienestar Social (Gráfico 7). En términos generales, aunque aumentó de forma moderada durante los primeros años de la crisis, a partir de 2011, una vez descontada la ficción presupuestaria de 2012, no solo no se mantuvo sino que además se redujo.

Gráfico 6. Evolución de los niveles de integración social en España (2007- 2013) y en la Comunidad Valenciana (2013)

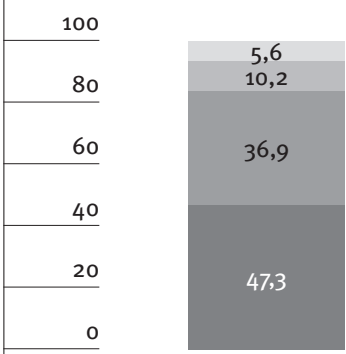

España 2007

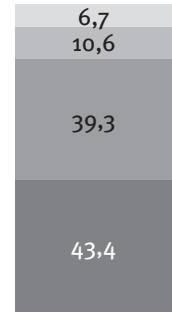

España 2009

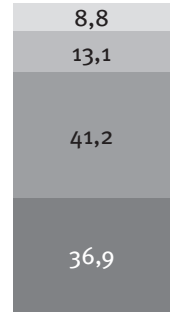

España 2013

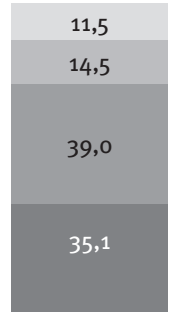

Comunidad Valenciana 2013

Exclusión severa

Exclusión moderada

Integración precaria

Integración plena

Fuente: Eins-Foessa, 2007, 2009 y 2013.

Gráfico 7. Evolución en millones de euros del presupuesto de la Conselleria de Bienestar Social (2008-2013)

$1.200,00$

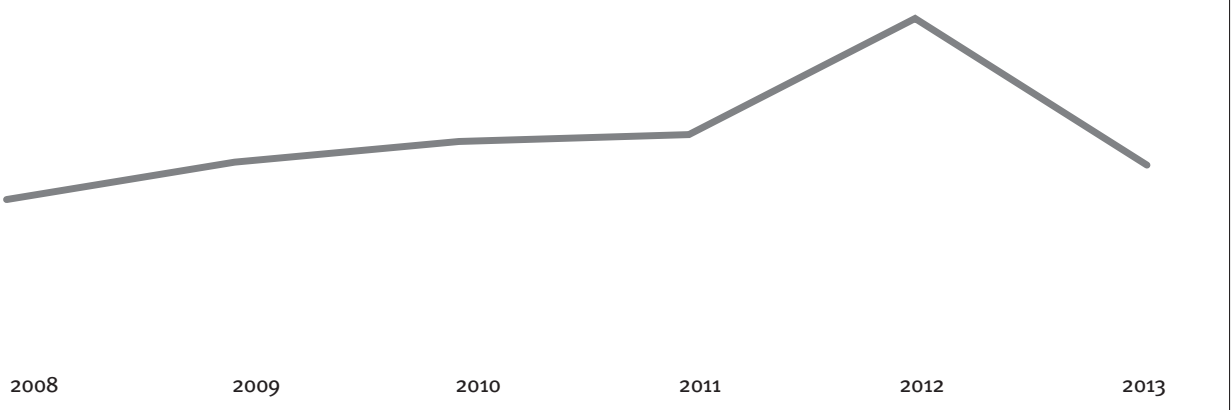

Fuente: Síndic de Comptes, 2015. 
Si centramos la atención en los presupuestos autonómicos relacionados con la actividad de los servicios sociales de atención primaria, podremos aproximar cuáles han sido los medios dispuestos para hacer frente a esta situación de emergencia. El Gráfico 8 presenta, mediante el examen de las memorias del PCPB y del SIUSS, la evolución del esfuerzo financiero de cada Administración en su sostenimiento. En primer lugar, observamos que al iniciarse la crisis su volumen crece de manera robusta hasta su máximo histórico en 2009, para posteriormente durante la fase más aguda de la crisis no dejar de disminuir. Ya en 2013 volverá a crecer, pero sin superar en ningún caso la cifra alcanzada con anterioridad. Aunque la Administración autonómica no dejó de incrementar su aportación al plan desde 2007, únicamente compensó la disminución en las aportaciones de los otros dos participantes sin elevar el volumen total. En otro orden, cabe destacar que el esfuerzo del plan se concentró a partir de 2011 en dotar de fondos la partida destinada a prestaciones económicas en detrimento de la de personal. Como consecuencia, los profesionales contratados pasaron de 2.629 en 2007 a poco más de 2.000 en $\mathbf{2 0 1 3}$, mientras se doblaba el número de prestaciones económicas. Así, de las 44.043 concedidas en 2008 se pasó a las 87.307 en 2013, siempre a un ritmo inferior al nacional y con una ligera oscilación de la cuantía de la prestación media concedida (de 245 euros en 2007 a 281 euros en 2013).
En lo que respecta al gasto en prestaciones económicas ligadas a los servicios sociales generales, los datos también son elocuentes. Entre el inicio de la gran recesión y 2014, la evolución del gasto en ayudas de emergencia ha sido errático, con subidas y posteriores recortes. Un comportamiento que también encontramos, aunque con menor brusquedad, en la evolución de las partidas destinadas a rentas mínimas de inserción (RMI), el otro instrumento económico esencial con el que cuentan los equipos de base para atender las situaciones de pobreza y exclusión. Si miramos con detenimiento el Gráfico 8, se observa una conducta correlativa entre el número de beneficiarios de las ayudas de emergencia y el gasto realizado en dicho concepto. La suma de estas cifras evidencia la total insuficiencia económica para atender las posibles demandas de ayuda. Varios hechos apuntalarían esa idea. Sabemos que el esfuerzo presupuestario de la Generalitat Valenciana para la financiación de las RMI ha sido durante estos años el más bajo de entre todas las comunidades autónomas (MSISS, 2015). También que el porcentaje de intervenciones realizadas por los equipos base para ayudas de emergencia y otras ayudas económicas aumentó en torno a un $9 \%$ entre el año 2008 y 2009 (SIUSS; 2012), mientras que el gasto no lo hizo nunca en términos equivalentes. Con ello queremos hacer notar de nuevo que en ningún caso el incremento producido ha sido acorde con la gravedad de la situación de pobreza de la población ni ha permitido atender sus demandas de ayuda.

\section{Gráfico 8. Evolución del PCPB en la Comunidad Valenciana (2007-2015)}

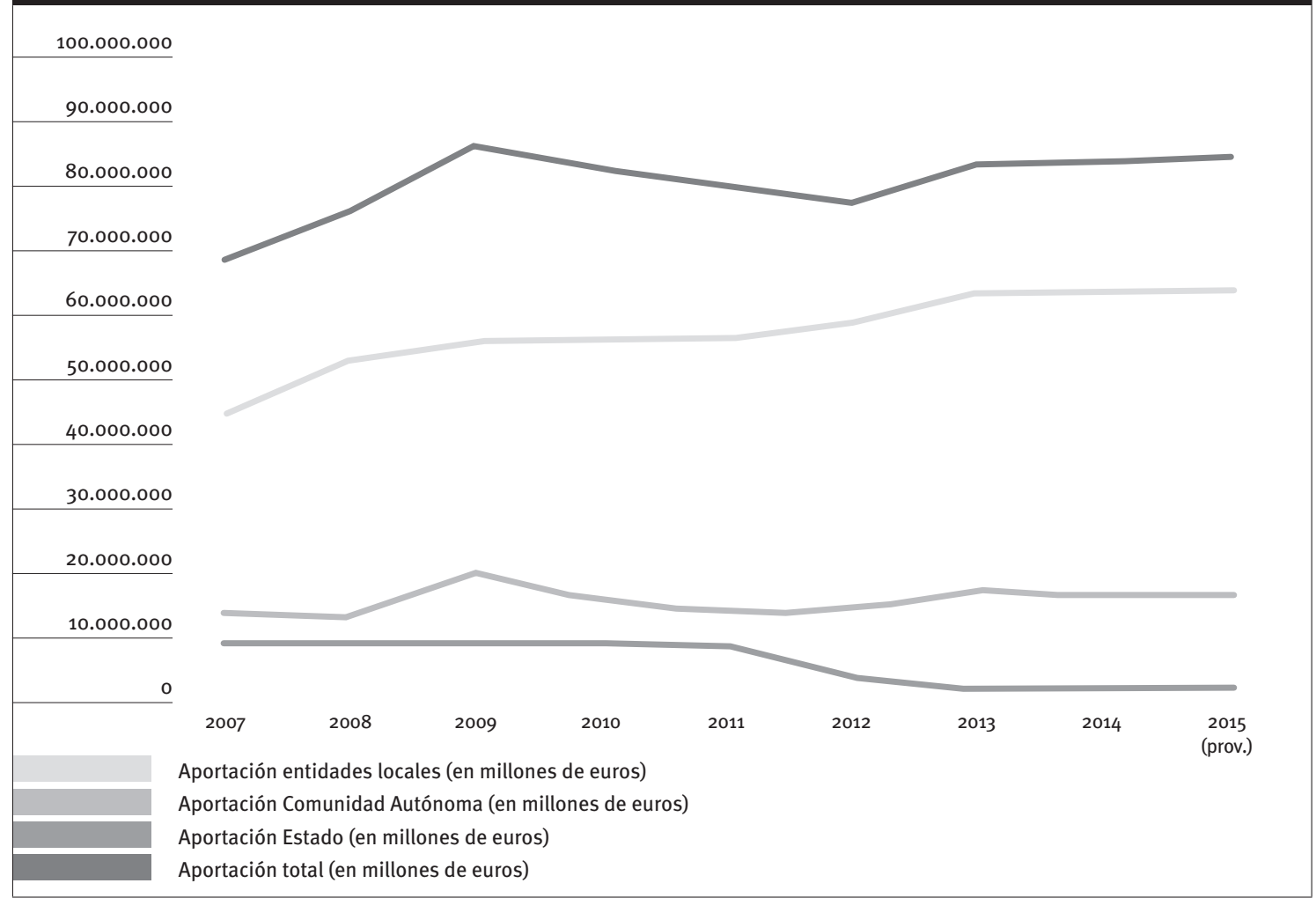

Fuente: Lluch y Esteve (2015). 
30.000 .000

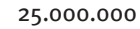

20.000 .000

15.000 .000

10.000 .000

5.000 .000

0

2008

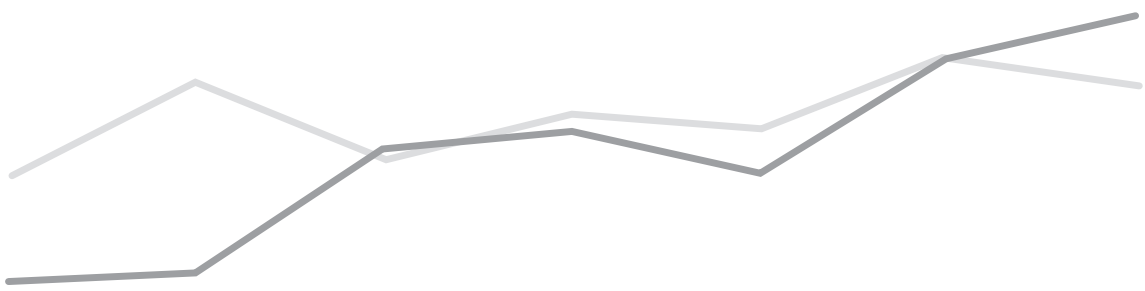

$$
2009
$$

2010

2011

2012

2013

2014

Gasto total en ayudas de emergencia (en millones de euros)

Gasto total ejecutado en Renta Mínima de Inserción (en millones de euros)

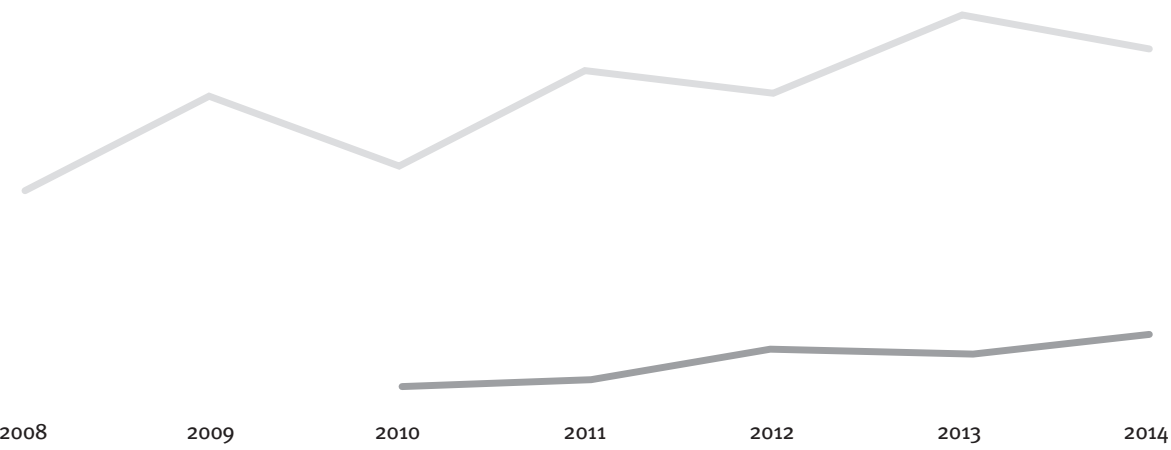

Total de perceptores de ayudas de emergencia

Total perceptores titulares de Renta Mínima de Inserción

Fuente: Ministerio de Sanidad, Servicios Sociales e Igualdad (SIUSS, 2012).

Podemos reforzar este argumento contrastando durante el mismo periodo la evolución del número de usuarios de servicios sociales generales en el conjunto nacional y autonómico. Mientras la tendencia nacional es de incremento sostenido desde el inicio de la crisis, en el caso de la CV ocurre lo opuesto: la pérdida de usuarios. Podría interpretarse como un signo de la escasa esperanza de los valencianos susceptibles de solicitar prestaciones o ayudas de que sus servicios sociales municipales pudieran proveerles. Una pauta que confirma el estudio de Tezanos (2013) y contrasta con las estadísticas de varias entidades del tercer sector en la CV (Cáritas, Cruz Roja, Casa Caridad) que vieron durante ese mismo periodo llegar a triplicar el número de personas que atendían y a las que prestaban ayuda.

Ahora bien, ante la falta de medidas y de esfuerzo por parte del Gobierno autonómico, nos deberíamos preguntar cómo evolucionó el gasto en servicios sociales generales en las entidades locales de la Comunidad Valenciana. A pesar de las dificultades que entraña, contamos con dos datos que pueden ayudarnos. El primero proviene del análisis de las aportaciones que un número determinado de ayuntamientos de la CV hicieron al PCPB desde 2007 hasta 2014. Como muestra el Gráfico 11, la mayoría de ellos redujo sus aportaciones, seguramente como consecuencia de las restricciones impuestas por el Gobierno central pero también sin duda por las dificultades económicas de las propias entidades locales para asumir mayor esfuerzo ${ }^{1}$. Otro informe, este de la AEDGSS (2016), pese a las deficiencias metodológicas señaladas por Manzano $(2016)^{2}$, confirmaría la tendencia regresiva de los presupuestos municipales en el capítulo de servicios sociales y promoción social. De los 33 ayuntamientos existentes de la CV con más de 20.000 habitantes

${ }^{1}$ No obstante, un informe del Síndic de Greuges de la CV (2013) considera que es posible que los ayuntamientos hayan hecho un esfuerzo superior al declarado. No es posible confirmarlo al persistir las dificultades para comprobar si el gasto imputado por las entidades locales de la CV se corresponde únicamente a servicios sociales generales o se imputan otro tipo de actividades y servicios (tercera edad, juventud y ocio, etc.).

${ }^{2}$ Manzano, M. (2016): "Els rànquings en serveis socials els carrega el diable” [〈www.lleiengel.cat〉], 12/12/2016. 


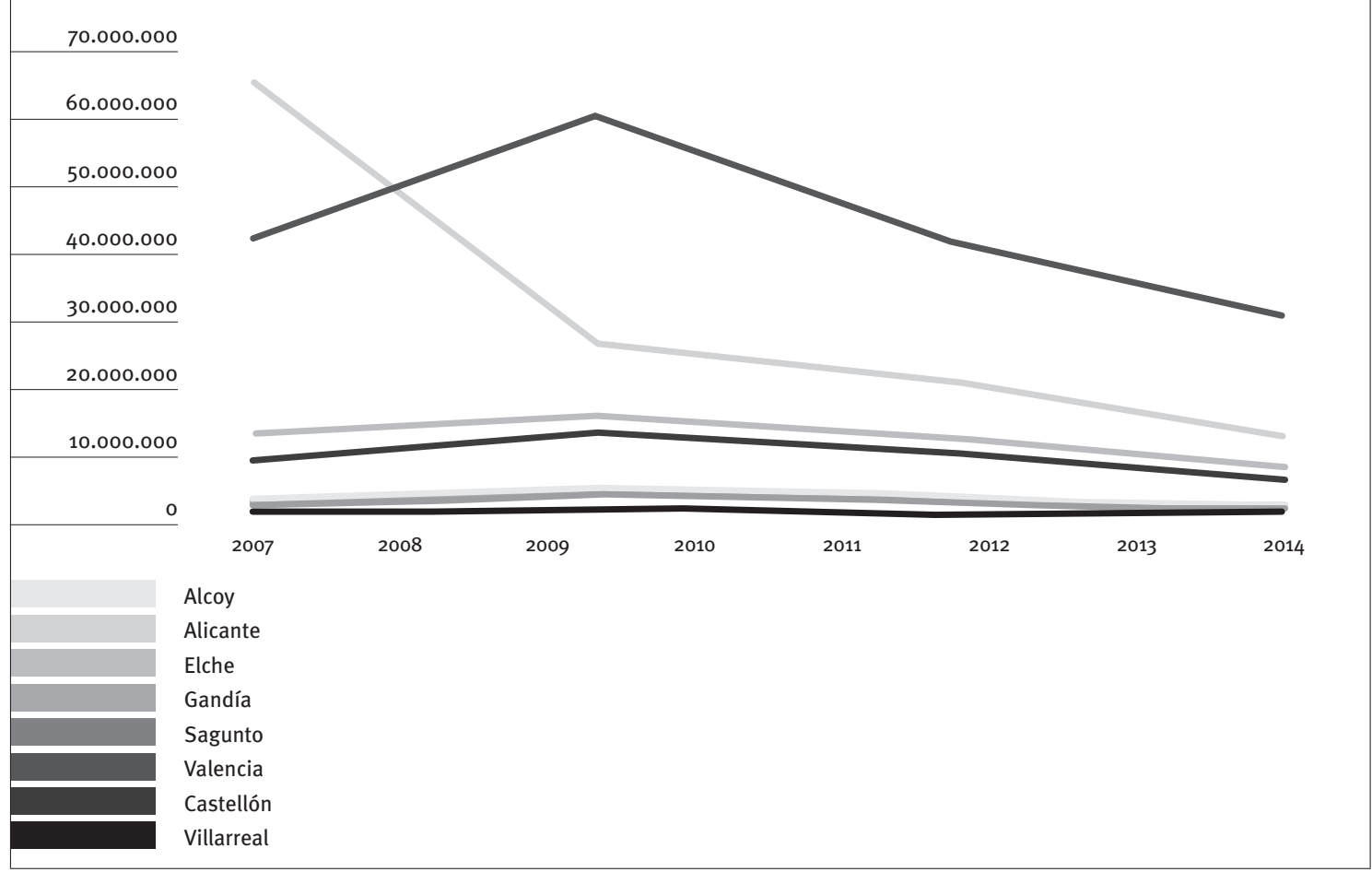

Fuente: Lluch y Esteve (2015).

analizados en el estudio, ninguno superaba hasta 2015 la calificación de "presupuesto precario de servicios sociales", es decir, que destinaban menos de 50 euros por habitante y año, y de ellos 12 podían incluso calificarse como pobres en servicios sociales (menos del $60 \%$ de la mediana) ${ }^{3}$.

En el caso de la Comunidad Valenciana, la debilidad de sus servicios sociales no ha sido únicamente una consecuencia de la crisis económica, sino una peculiaridad desde sus inicios. A pesar del esfuerzo inicial por construir una red pública de atención primaria, el gasto que ha representado en términos comparativos siempre ha sido inferior al de la media nacional, como también lo ha sido la ratio de profesionales/población o el número y volumen de prestaciones económicas. Además, esta situación empeoró desde mediados de los noventa, cuando se trasladó parte del esfuerzo a atender la creciente demanda de servicios sociales especializados. Sin embargo, a partir de 2003 se produjo el periodo de mayor crecimiento continuado en materia de personal y prestaciones en la atención primaria, al pairo de la bonanza económica aunque sin conseguir recuperar el terreno perdido.

3 Nota de Prensa de la AEDGSS 10/11/2016. Disponible en [<http://www.directoressociales.com/prensa/397-solo-12-ayuntamientos-alcanzan-la-excelencia-en-inversión-social,-mientras-que37-pueden-considerarse-oficialmente-pobres-en-servicios-sociales. html>].

\section{Limitaciones del sistema público de servicios sociales en la Comunitat Valenciana}

Ante este panorama, son mayoría quienes responsabilizan de la situación a la deficiente inversión como única culpable. Esa es la posición defendida por diversas entidades (AEDGSS, 2015; Síndic de Greuges de la CV, 2013; 2017) e investigadores (Martínez y Uceda, 2015; Mateo, Martínez y Doménech, 2015). Todos ellos tienen en común establecer un vínculo entre la inversión en servicios sociales y la capacidad para detener o paliar los efectos más graves de la crisis. Nos detendremos en el análisis de dos de ellos. La Asociación de Directores y Gerentes de Servicios Sociales (AEDGSS) viene publicando anualmente desde 2012 el índice DEC, que mide el desarrollo de estructuras y presupuestos en el sistema. Pese a sus objeciones metodológicas, se trata de uno de los pocos intentos de establecer un sistema de medición que aglutine todos los servicios sociales de las comunidades autónomas, lo que permite compararlos. En él, la Comunidad Valenciana aparece como la peor situada en esfuerzo y estructura de servicios sociales y por debajo de la media estatal en 13 de los 14 indicadores que mide. Conforme a este estudio, la Comunidad Valenciana en 2014 destinó 204 euros frente a los 611 del País Vasco y el gasto conjunto en servicios sociales de las administraciones local y autonómica supuso para la CV un 5,89\% frente al 9,67\% del conjunto en la Comunidad de Castilla La Mancha (AEDGSS, 2015). Para esta asociación, el 


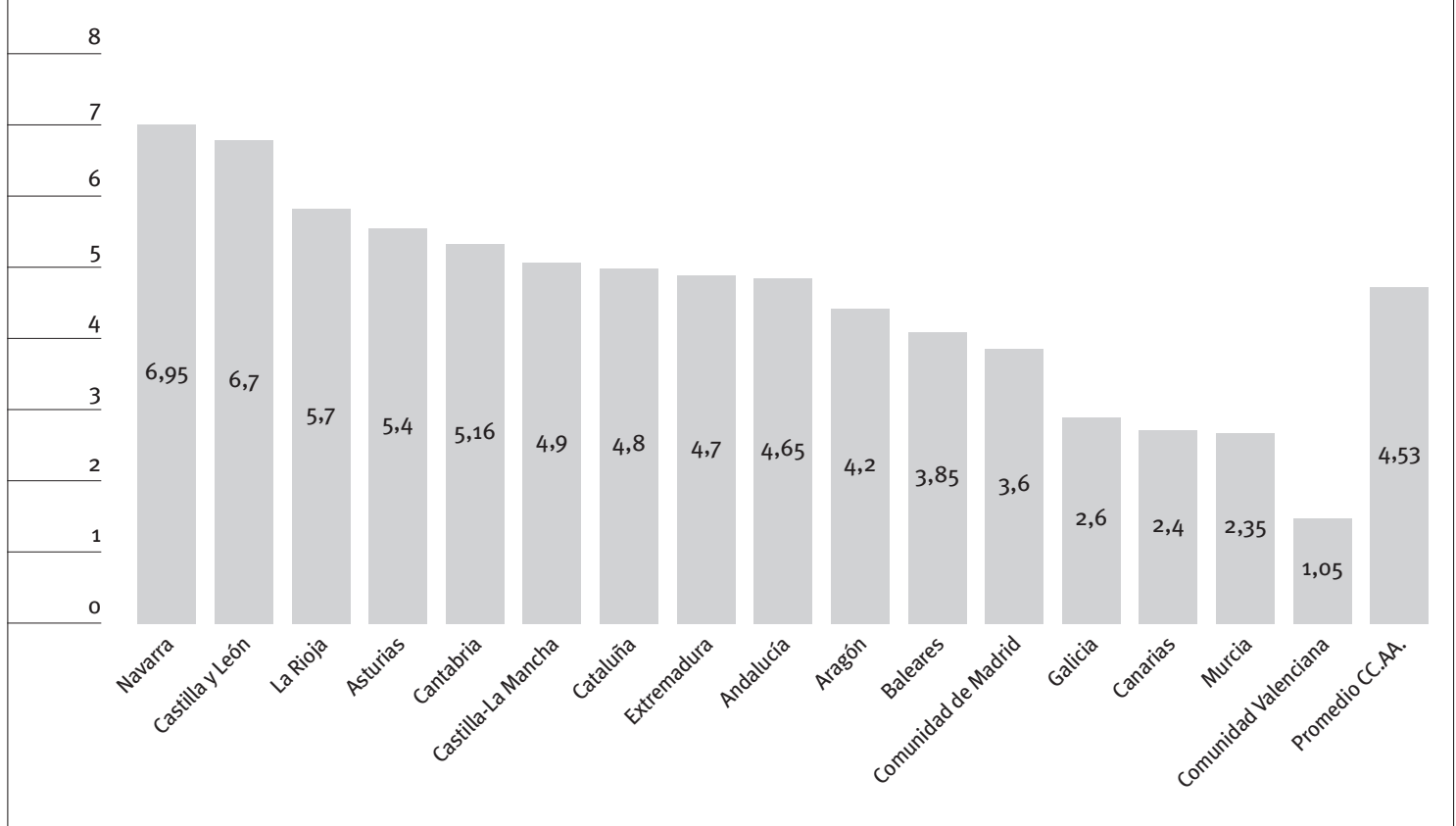

Fuente: Lluch y Esteve (2015).

sistema público de servicios sociales valenciano es

el más deficiente de los estudiados, considerándolos "irrelevantes" como instrumento de bienestar. Por este motivo, estiman que el esfuerzo económico que debería realizar esta comunidad para situarse dentro de los parámetros medios estatales sería de 566 millones de euros más al año.

Otro estudio, este de distinto alcance, es el realizado por Mateo, Martínez y Doménech (2015). Sobre la base del estudio de la AEDGSS y del PCPB y apoyados por otros indicadores, estiman que existe una relación directa entre el nivel de desarrollo de los servicios sociales de cada Comunidad Autónoma y la incidencia de los procesos de pobreza y exclusión social en ese territorio. La hipótesis que guía su investigación es que, en el marco del Estado de Bienestar, el incremento de los riesgos de pobreza y exclusión social de una población debería implicar necesariamente el fortalecimiento de los sistemas públicos de protección social, especialmente de los servicios sociales, pues son estos los que pueden ofrecer recursos y actuaciones centradas en su prevención e inclusión social. Para probarlo, complementan el índice DEC con otros indicadores de pobreza y exclusión (índice Arope, índice GINI [〈https://es.wikipedia.org/wiki/Coeficiente_de_Gini〉], tasa de desempleo, etc.) y de servicios sociales generales (porcentaje de usuarios sobre el total de población, proyectos financiados, etc.) mediante la aplicación del modelo ANOVA. A partir de él, establecen una clasificación de las comunidades autónomas (débil, medio y fuerte) atendiendo al grado de desarrollo de sus sistemas, que sitúa a la Comunidad Valenciana en la categoría más baja. Sin embargo, su estudio les lleva a constatar que "cuanto más paro y más riesgo de exclusión social detectamos en una región, más débil es su sistema de servicios sociales” (Mateo, Martínez y Doménech, 2015: 13). Una conclusión que coincide con el análisis de Carro y Míguez (2013), quienes enuncian esta situación como la paradoja del Estado asistencial: cuanto mayores son las necesidades sociales a las que el sistema debe atender, menor es la capacidad para darles respuesta.

Todos estos argumentos de sobra conocidos contrastan con la opinión de otros investigadores y profesionales. A su juicio, la acción de los servicios sociales generales tropieza cada vez con mayores obstáculos para generar cambios o mejoras sostenibles en las vidas de las personas a las que se dirige. Dificultades que no pueden achacarse única o esencialmente a la falta de recursos, pues su aumento no es garantía de mejora de las situaciones de pobreza extrema y exclusión con las que trabajamos. Al menos no en la intensidad, extensión y estabilidad que cabría haber esperado durante el periodo de bonanza económica. Por consiguiente, no debería inferirse una relación única y directa entre los índices de pobreza y exclusión social y su nivel de desarrollo, ni tampoco lo contrario. Esto nos ha llevado a sospechar que lo que venimos considerando como "dificultades" podría estar enmascarando en realidad serios obstáculos del sistema tal y como hoy está definido que actuarían como verdaderos límites a las posibilidades de intervención de los servicios sociales (Montagud, 2012, 2016).

Aún es más cierto que los servicios sociales están sujetos en estos momentos de crisis y cambio de época a las mismas limitaciones que otras ramas del Estado de Bienestar. La proclama del fin de esta era como resultado del declive del viejo estado westfaliano y de los estados modernos 
en combinación con el irrefrenable proceso de globalización e individualización no es una idea nueva, pero sí está ganando cada vez mayor aceptación académica. En esa dirección apuntan los textos de Rojas (2014), Micklethwait y Wooldridge (2015) al los que se suman los de López Casasnovas (2015) y Subirats y Vallespin (2015: 40), para quienes “nada volverá a ser lo mismo o, si se prefiere, [...] hacer lo que siempre hemos hecho no nos garantiza volver a dónde estábamos antes”. Incluso alguien tan respetado como Piketty (2015) asume el declive del modelo de Estado expansivo, solo preocupado por financiar las necesidades de sus ciudadanos. Considera que ha llegado el momento de que el Estado deje de crecer y se centre en discutir su organización, modernización y consolidación, a sabiendas de que, con bastante seguridad, su capacidad para intervenir no va a aumentar sino a disminuir. Sin entrar de lleno en el asunto, resumiremos que son la resistencia a una mayor presión fiscal, la aparente ineficacia de algunos de los programas sociales implementados y la pérdida de legitimidad de la acción pública como actor exclusivo, junto con los procesos de complejidad, individualización y globalización, los factores que configuran el cambio de época. Ellos condicionan el futuro de cualquier forma de política social que se pretenda y, por ende, las posibilidades de los servicios sociales para poder llevar a cabo su misión.

En este contexto, la posibilidad de que los servicios sociales de atención primaria en la Comunidad Valenciana puedan crecer lo suficiente para recortar la amplia distancia que les separa de la media nacional es más bien escasa y restringida a momentos y situaciones concretas. A pesar del esfuerzo iniciado por el nuevo Gobierno valenciano en 2015 para suplir y superar ese retraso, la posibilidad de recomponer el sistema bajo los mismos principios y objetivos con los que se crearon parece ser lejana. No solo por las condiciones restrictivas del gasto público a las que se enfrenta o por los retos pendientes de resolver en los sistemas de protección social y de los servicios sociales identificados por Aguilar (2014), Fantova (2016), Pelegrí (2015) o Zalakain (2016), sino también por la creciente colisión de intereses que se concitan:

a. Continuar respondiendo bajo el principio estricto de universalidad a los derechos subjetivos vigentes generados en el ámbito de los servicios sociales (Ley de Dependencia) y los que están en proyecto (Renta Valenciana de Inclusión) o asumir la necesidad de restaurar algunas medidas restrictivas de acceso a ciertas prestaciones y servicios.

b. Priorizar las demandas de determinados sectores de población, que obligan a contraer un porcentaje de gasto cada vez mayor o atender las necesidades de otros sectores desatendidos de población en situación de exclusión o pobreza.

c. Seguir siendo el ámbito de gestión preferente en el que diferentes Administraciones depositan la tramitación y seguimiento de ciertas prestaciones de carácter subjetivo y discrecional o delimitar su objeto y abordar las fallas de la intervención de proximidad.

d. Responder de forma estandarizada a los problemas específicos de una población con necesidades particulares o buscar alternativas que permitan ofrecer servicios adaptados a esas necesidades.

e. Cumplir los requerimientos normativos y de control de una Administración cada vez más burocratizada y protocolizada o abrirse a incorporar modelos flexibles de gestión de la intervención con los entornos sociales con los que convive.

f. Apostar por un modelo exclusivamente administrativista pero limitado, o buscar un nuevo marco de colaboración con las entidades del tercer sector que intervienen desde la proximidad.

Existen señales sobre algunos de estos conflictos. La supresión en $\mathbf{2 0 1 5}$ del copago en la prestación de ciertos servicios de la Ley de Dependencia supuso asumir 24,5 millones de euros más de gasto en $2016^{4}$, una cuantía mayor que el aumento de dotación de la Generalitat Valenciana para el PCPB en 2017 y muy superior al aumento de 3,8 millones de euros del presupuesto en la renta de ciudadanía para ese mismo año (que asciende a 41 millones de euros). Además, el aumento en la partida del PCPB tiene dos particularidades: prioriza la contratación de personal en detrimento de las prestaciones económicas e incluye como contrapartida la obligación de los servicios sociales de base de valorar, tramitar y gestionar la solicitudes de dependencia y asumir las de la renta de ciudadanía. Todo ello podría repercutir con bastante probabilidad en su funcionamiento y capacidad, incrementando las tareas de gestión y control de las que tratan de escapar. También se adivina en las dificultades para aprobar y desplegar desde su actual concepción de derecho universal subjetivo la futura Renta Valenciana de Inclusión -sobre la que no hay ningún cálculo aproximado de su coste- mientras la vigente continúa protegiendo a un porcentaje muy reducido de sus potenciales beneficiarios. Se observa además cómo ciertas entidades, programas y servicios del tercer sector, arraigados en el territorio, ganan liderazgo y reconocimiento de la comunidad. Y, por último, en la práctica desatención al problema de la pobreza infantil en la Comunidad Valenciana a pesar de que afecte aproximadamente a 4 de cada 10 niños y niñas.

En conclusión, los servicios sociales de atención primaria de la CV son contemplados hoy por una buena parte de la ciudadanía como un órgano distribuidor de recursos y servicios mediatizado por la burocracia. En

${ }^{4}$ Nos referimos a la supresión del copago para beneficiarios con cierto nivel de rentas en centros de día diurnos y a la eliminación de las pagas extra en el cálculo del derecho a servicios o prestaciones de la Ley de Dependencia. 
ese sentido, la fractura del paradigma sobre el que se asentó la fundación del sistema público de servicios sociales de atención primaria - ser el pilar y puerta de entrada- y el contexto socioeconómico que ha dejado la recesión abren nuevas perspectivas. Si seguimos las cuatro dimensiones analíticas del bienestar (financiación, provisión, decisión y regulación) y los posibles modelos de régimen resultantes de combinarlos (Aliena, 2012), observamos esos cambios. En el caso de los servicios sociales, aunque siguen siendo con diferencia las Administraciones los principales financiadores, se constata el creciente papel de algunas fundaciones e instituciones ajenas al sector público en la financiación de proyectos de intervención social de proximidad. En la Comunidad Valenciana, tras el derrumbe de las cajas de ahorro valencianas, cabe reseñar por su significado e importancia, el papel creciente de la Fundación La Caixa. No solo en la financiación de determinados programas como Prolnfancia $u$ otros proyectos dirigidos al apoyo del tercer sector y de empresas sociales, sino por la significación de los convenios de colaboración entre la Generalitat Valenciana y la Fundación, que se concretan en una convocatoria anual de ayudas a proyectos de iniciativas sociales que inciden en la protección de menores, personas mayores y otros colectivos en situación de especial vulnerabilidad5. Si nos detenemos en la provisión de esos servicios, pese a que la titularidad sigue recayendo en el espacio público, cada vez es mayor el número de entidades que proveen directamente servicios sociales de proximidad en su comunidad cercana y que se imponen como referentes para los ciudadanos que se acercan a ellos. Esta pluralidad en la financiación de los servicios sociales también ha afectado a la forma de tomar decisiones sobre la dirección de la intervención social en el territorio, que ha llevado a que las Administraciones se hayan abierto a la participación de otros agentes sociales. Algo similar a lo ocurrido con la dimensión reguladora. Otrora competencia exclusiva de la Administración Pública, hoy precisa de la colaboración de los agentes sociales presentes en el sector a la hora de fijar objetivos, estándares o restricciones dados sus conocimientos, peso e importancia. Como resultado de todas esas transformaciones y condicionantes, creemos que ha llegado el momento de replantear la naturaleza de los servicios sociales generales de modo que aseguren su sostenibilidad y puedan cumplir con la misión encomendada.

\section{Conclusiones}

En el caso de la Comunidad Valenciana, creemos probada la debilidad de su sistema de servicios sociales generales. Los datos ofrecidos así lo
${ }^{5}$ Para hacernos una idea de su importancia, la Fundación La Caixa aprobó, solo en la línea de prevención de pobreza infantil para la Comunidad Valenciana en 2016, nueve proyectos con una financiación total de 258.750 euros, mientras que la Generalitat Valenciana aportó 351.480 euros a la única línea asignada a ese objetivo, proveniente de un convenio con el Estado (total 948.520 euros). confirman. Sin embargo, descubrimos que tal debilidad no es una consecuencia del abandono premeditado de una opción política concreta o un efecto de los recortes producto de la crisis, sino el resultado de un modelo que ha sido precario desde su nacimiento. Al menos así lo indica el análisis de la evolución del PCPB en la CV si se coteja con la del conjunto del Estado. Los servicios sociales de atención primaria de la CV no recibieron la atención suficiente durante los primeros años en comparación con otros territorios del Estado. Después, desde mediados de los noventa, hubieron de competir contra el proceso de individualización, el triunfo de la idea del ciudadano-consumidor y otros cambios económicos, demográficos y sociales. A resultas de estos, los servicios sociales generales perdieron el impulso y el liderazgo de la proximidad que ha sido ocupado paulatinamente por las entidades del tercer sector allí donde han podido implantarse y crecer. La crisis ha probado las dificultades de este nivel básico para afrontar la intervención contra las manifestaciones más severas de la crisis mientras las entidades del tercer sector y de otras formas de iniciativa social desplegaron, a menudo con escasos medios, una respuesta ágil y rápida.

Con independencia de si esta situación ha sido provocada o si se le atribuye el calificativo de asistencialista a algunas iniciativas sociales aparecidas al pairo de la crisis, lo que a nuestro entender se evidencia, es la incapacidad de este sistema en las circunstancias actuales, para hacer frente por sí solo a las situaciones de emergencia social. Pero las consecuencias de la crisis no han acabado ahí. Han puesto al descubierto las limitaciones de un discurso centrado casi exclusivamente durante todos estos años en la gestión de recursos concebidos como derechos ilimitados que difícilmente serán satisfechos sin entrar en colisión con otros (Carro y Miguez, 2013; Garcés Sanagustín, 2012).

El cambio de rumbo iniciado por el nuevo Gobierno valenciano en 2015 y las iniciativas emprendidas parecen haber renovado el impulso a la atención primaria. No obstante, persistimos en considerar que, a pesar de los avances, será improbable constituir un sistema público que pueda por sí solo hacer frente a la pobreza y exclusión crónicas $y$, a la vez, afrontar los nuevos retos. Hoy por hoy la sostenibilidad del sistema -tal y como aquí la hemos entendido - no está garantizada desde el marco desde el que se ha venido desarrollando exclusivamente hasta ahora. La crisis ha demostrado las restricciones de las entidades locales y de la Generalitat para afrontar un nuevo escenario en el que la vulnerabilidad, la desigualdad, la pobreza y la exclusión deberán coexistir con dificultades crecientes para obtener financiación y a la vez satisfacer la multiplicidad de exigencias de la ciudadanía y la sociedad civil. La sociedad valenciana no es la que era cuando se crearon, ni los servicios sociales generales serán lo que confiábamos que fueran, como tampoco el Estado de Bienestar, tal 
y como lo hemos conocido, volverá a ser el mismo. En consecuencia, creemos superado el marco fundacional con el que se instituyeron hace treinta y cinco años los servicios sociales generales. Pero no nos equivoquemos. No se trata de eliminar, apartar o privatizar lo que tenemos, sino de encontrar cómplices en el territorio. Los municipios, las comunidades, son hoy un espacio en el que los problemas conocidos comparten lugar con nuevas fragilidades y formas de exclusión. Un lugar en el que los problemas han mutado hacia una complejidad no exenta de cierto carácter maldito que impide ver avances o soluciones en el corto y el medio plazo. Un espacio en el que la tradicional demanda de recursos se enfrenta a la urgencia por recuperar los bienes relacionales, en el que a pesar de repuntar el interés por lo comunitario, seguimos centrando la mayoría de esfuerzos en lo individual. Todos estos cambios nos reafirman en la idea de que la sostenibilidad de los servicios sociales de proximidad solo será posible en el futuro desde un nuevo modelo que reconozca el peso e importancia de las entidades sociales, incorporándolas plenamente en su gobernabilidad. Es en ese nuevo terreno en el que los municipios deberán estudiar y abordar la configuración y provisión de sus servicios sociales por otros medios, asumiendo así los principios de la gobernanza pública para el ámbito local. 
AEDGSS (2015): Índice de desarrollo de los Servicios Sociales 2015, Madrid, Asociación Estatal de Directoras y Gerentes de Servicios Sociales, [<http://www.directoressociales.com/images/ INDICEDEC/ccaa\%2odec\%202015.pdf)].

AGUILAR, M. (2013): "Los servicios sociales en la tormenta", Documentación Social, n. 166, pp. 145-167.

- (2014): VII Informe sobre exclusión y desarrollo social en España. Apuntes para un replanteamiento de los servicios sociales en España, Madrid, Fundación Foessa.

ALGUACIL, J. (2012): "La quiebra del incompleto sistema de Servicios Sociales en España", Cuadernos de Trabajo Social, n. 25, p. 63-74 [shttp://dx.doi. org/10.5209/rev_CUTS.2012.v25.n1.38434'].

ALIENA, R. (2012): "Regímenes de bienestar y política social por otros medios: un marco analítico", Comunitania, n. 4, p. 10-42 [rhttp://dx.doi. org/10.5944/comunitania.4.1〉].

CARRO, J. L. y MIGUEZ, L. (2011): "Servicios Sociales y crisis económica: los límites del estado asistencial” (comunicación), VI Congreso de la Asociación Española de Profesores de Derecho Administrativo, 11-12 de febrero 2011, Palma de Mallorca.

EAPN-ESPAÑA (2016): El Estado de la pobreza. Seguimiento del indicador de riesgo de pobreza y exclusión social en España 2009-2015 [<http://www. sociales", Documentación Social, n. 175 p. 105-132.

- (2016): "Nuevos enfoques para los servicios sociales ante la nueva realidad social", Revista Española del eapn.es/estadodepobreza>].

FUNDACIÓN FOESSA (2014): Informe sobre exclusión y desarrollo social en la Comunidad Valenciana, Madrid, Fundación Foessa [rhttp:// www.foessa2014.es/informe/uploaded/ ccaa/20112014030054_3429.pdf)].

FUNDACIÓN LA CAIXA (2015): Programa de Ayudas a Proyectos de Iniciativas Sociales. Comunitat Valenciana [<https://obrasociallacaixa.org/es/ convocatorias〉].

FUNDACIÓN LUIS VIVES (2012): Anuario del Tercer Sector de Acción Social en España [rhttp://www. luisvivesces.org/upload/95/52/2012_anuario_ tsas.pdf〉].

GARCÉS SANAGUSTÍN, A. (2012): Los nuevos retos de los servicios sociales en España, Zaragoza, Editorial Epraxis.

GUTIÉRREZ RESA, A. (2003): “El Plan Concertado de Prestaciones Básicas de Servicios Sociales en España (Once años del Plan Concertado)", Revista Española de Investigación Social, n. 93, p. 89-130 [<http://www.reis.cis.es/REIS/PDF/ REIS_093_06.pdf〉].

LÓPEZ CASANOVAS, G. (2015), El bienestar desigual, Barcelona, Ediciones Península.

LLUCH, E., ESTEVE, E. y GIMENO, B. (eds.) (2015): Crisis y derechos sociales. Análisis y perspectivas. Comunitat Valenciana 2014, Madrid, Fundación Foessa.

MARTINEZ, L. y UCEDA, X. (2015): “Presente, pasado y futuro de los Servicios Sociales Municipales en la Comunitat Valenciana", TS nova, n. 11, p. 69-90. Tercer Sector, n. 33, p. 113-139.
A., MARTíNEZ, M. A. y DOMENECH, Y. (2015): "Social Services in times of economic and social crisis: The case of spain", Revista de Cercetare si Interventie Sociala, n. 50, p. 96-110. 
MICKLETHWAIT, J. y WOOLDRIDGE, A. (2015): La cuarta revolución. La carrera global para reinventar el Estado, Barcelona, Galaxia Gutenberg.

MINISTERIO DE SANIDAD, SERVICIOS SOCIALES E IGUALDAD (2015): Memoria del Plan Concertado de Prestaciones Básicas de Servicios Sociales en Corporaciones Locales, Madrid, MSSSI [<https://www.msssi.gob. es/ssi/familiasInfancia/inclusionSocial/ serviciosSociales/planConcertado/home.htm〉].

MONTAGUD, X. (2016): “Las consecuencias de la burocratización en las organizaciones de servicios sociales", Comunitania, n. 11, p. 69-89 [rhttp://dx.doi.org/10.5944/ comunitania.11.4>].

- (2012): “Aproximación a los límites de la intervención social. Obstáculos y dificultades epistemológicas", en FOMBUENA, J. (ed.): $E l$ trabajo social y sus instrumentos, Valencia, Nau llibres.

PELEGRÍ, X. (2015): “Repensant la política de serveis socials per a un canvi d'època", Pedagogía i Treball Social, n. 4, p. 52-72.

PIKETTY, T. (2015): El capital en el siglo XXI, México, Fondo de Cultura Económica.

RITZER, G. (1999): Enchanting a discenchanted world: Revolutionizing the means of consumption, Londres, Sage.
RODRÍGUEZ CABRERO, G. (coord.) (2012): Servicios Sociales y cohesión social, Madrid, Consejo Económico y Social.

ROJAS, M. (2014): Reinventar el Estado de Bienestar. La experiencia de Suecia, Madrid, Gota a Gota Ediciones.

SIINDIC DE GREUGES C.V. (2017): El papel de los servicios sociales generales en la lucha contra la pobreza y la exclusión en los municipios valencianos durante la crisis, Síndic de Greuges de la Comunitat Valenciana [<http://www.elsindic. com/documentos/635_SINDIC\%2olibro\%20 Pobreza\%2oCAST.pdf $>$ ].

- (2013): Situación de los servicios sociales generales en la Comunitat Valenciana, Alicante, queja n- 1211322 [khttp://www.elsindic.com/ Resoluciones/10561033.pdf)].

SUBIRATS y VALLESPIN (2015): España/Reset. Herramientas para un cambio de sistema, Barcelona, Ariel.

SUBIRATS, J. (Ed.) (2007): Los Servicios Sociales de Atención Primaria ante el cambio social, Madrid, Ministerio de Trabajo y Asuntos Sociales.

TEZANOS, J. et al. (2013): En los bordes de la pobreza. Las familias vulnerables en contextos de crisis, Madrid, Biblioteca Nueva.

ZALAKAIN, J. (2016): "Nuevos retos para los sistemas de lucha contra la pobreza en la Unión Europea", Revista del Tercer Sector, n. 32, p. 173-201. 